\title{
Small Bodies Assessment Group Community Decadal Survey Summary
}

Bonnie J. Buratti (SBAG Chair; Jet Propulsion Laboratory, California Institute of Technology; Bonnie.Buratti@jpl.nasa.gov; 818-468-1401); Mark Sykes (Planetary Sciences Institute); and the SBAG Steering Committee (https://www.lpi.usra.edu/sbag/committee/)

Summary: SBAG surveyed the small bodies community for input to the Planetary Decadal Report. Seventeen questions on science and mission priorities were answered by 121 respondents. The highest priority scientific issues for small bodies were population identification and physical/compositional characterization; understanding the characteristics and evolution of individual objects; determination of the early conditions in the Solar System; and completion of the catalogue of PHAs. The highest priority flagship mission was a comet sample return followed by a Pluto orbiter/KBO mission. A comet sample return was also the highest priority New Frontiers mission, followed by a Ceres lander and a Main Belt multiple asteroid mission. Emphasis was also placed on the importance of ground-based and Earth orbiting telescopes (including radar), laboratory studies, and theory. The group also advocated preserving research funding over missions in the event of budget pressures.

Copyright 2020. All rights reserved. 
In advance of the Planetary Decadal Report, The Small Bodies Assessment Group Steering Committee conducted a survey between May 6-25, 2020 using SurveyMonkey to understand the planetary science community's priorities for science, missions, and facilities. Announcements were sent out by professional societies (Planetary Section of the AGU, Division for Planetary Sciences of the AAS) and the Planetary Exploration Newsletter (PEN). There were 121 respondents, 109 from U.S. institutions, 107 of whom received NASA funding. The full results of the survey are on SBAG's site (https://www.lpi.usra.edu/decadal/sbag/); this white paper summarizes the main results. The Questions are as follows:

1. Full Name

2. Affiliation/Institution

3. Email Address

4. I am currently funded by NASA or have received NASA funding in the past (Y/N)

5. In your own research, your priority targets (1=highest priority, 9=lowest priority)

a. Asteroids (including NEOs), Comets, Interplanetary Dust

b. Pluto-Charon, other Dwarf Planets

c. Jupiter, Saturn, Uranus, Neptune

d. Mercury, Venus, Earth, Mars

e. Titan, Triton, other large satellites

f. Small Satellites

g. Planetary Rings

h. Exoplanets

i. Other (please specify)

6. Highest Priority scientific issues for small bodies (1-highest priority, 9-lowest priority)

a. Understanding the characteristics and evolution of individual objects

b. Population identification and physical/compositional characterization

c. Population sources and sinks (dynamical and collisional evolution)

d. Comparing the history and processes of our Solar System with other solar systems (e.g., interstellar objects, exoplanet systems)

e. Understanding how the materials that initiate life were delivered to the habitable zone/Earth

f. Determining early conditions in the Solar System (e.g., compositional gradient, early formation history)

g. Searching for extant habitable zones

h. Completing the catalog of PHAs and their representative characteristics

i. Other

7. Question 6 Comment (Optional)

8. Highest priority Flagship mission (1-highest priority, 3-lowest priority)

a. Cryogenic Comet Sample Return

b. Pluto orbiter/KBO mission

c. Other (please specify)

9. Question 8 Comment (Optional)

10. Highest priority New Frontiers Missions (1-highest priority, 9-lowest priority)

a. Main-belt asteroid sample return

b. Comet surface sample return 
c. Multiple target flyby of satellite (e.g., Triton) and small TNO

d. Mega-multiple flybys of main belt asteroids

e. Jupiter Trojan flyby

f. Flyby of an explored ice dwarf (e.g., Haumea)

g. Multiple main belt asteroid rendezvous

h. Ceres lander

i. Other (please specify)

11. Question 10 Comment (Optional)

12. What are the most important science goals that can be addressed by Discovery-class missions?

13. What are the highest priority research facilities that need to be developed and/or supported? (1-highest priority, 6-lowest priority)

a. Access to large aperture ground-based telescope facilities

b. Radar facilities

c. Modest aperture ground-based telescope facilities dedicated to primitive bodies search and characterization

d. Laboratory support for meteorite studies and returned sample/analog characterization including advanced curation facilities such as cold curation of volatiles, long-term containment, and analysis of organic materials

e. Computational

f. Other (please specify)

14. Question 13 Comment (Optional)

15. Balancing priorities - in the event of negative budget pressure on the planetary budget, what is the priority for preserving program funding? (1-highest priority, 6-lowest priority)

a. New Frontiers-class missions

b. Discovery-class missions

c. Technology development programs

d. Flagship-class missions

e. Research and Data Analysis programs

f. Other (please specify)

16. Question 15 Comment (Optional)

17. What technology investments do you recommend?

\section{QUESTIONS 1-4, IDENTIFICATION AND NASA SUPPORT HISTORY}

The vast majority of the respondents came from the small bodies community, with $67 \%$ stating that asteroids were their prime targets of study; $11 \%$ Pluto, Charon, and other dwarf planets; $8 \%$ gas giants; $13 \%$ terrestrial planets; $9 \%$ exoplanets, $12 \%$ each large and small moons; $7 \%$ rings; and $34 \%$ other. The respondents came from a very broad distribution of this community across American academic institutions, non-profit and for-profit corporations, and government institutions.

\section{QUESTION 6: HIGHEST PRIORITY SCIENTIFIC ISSUES FOR SMALL BODIES}

Of the 121 respondents, the scientific issues sorted on the basis of how many ranked then in the top three for priority (see table below) are: 
75 - Population identification and physical/compositional characterization

61 - Understanding the characteristics and evolution of individual objects

51 - Determining early conditions in the Solar System (e.g., compositional gradient, early formation history)

44 - Completing the catalog of PHAs and their representative characteristics

28 - Population sources and sinks (dynamical and collisional evolution)

27 - Understanding how the materials that initiate life were delivered to the habitable zone/Earth

24 - Comparing the history and processes of our Solar System with other solar systems (e.g., interstellar objects, exoplanet systems)

16 - Searching for extant habitable zones

5 - Other

\begin{tabular}{|c|c|c|c|c|c|c|c|c|c|c|}
\hline & 1 & 2 & 3 & 4 & 5 & 6 & 7 & 8 & 9 & TOTAL \\
\hline $\begin{array}{l}\text { Understanding the } \\
\text { characteristics and evolution } \\
\text { of individual objects }\end{array}$ & $\begin{array}{r}21.50 \% \\
23\end{array}$ & $\begin{array}{r}16.82 \% \\
18\end{array}$ & $\begin{array}{r}18.69 \% \\
20\end{array}$ & $\begin{array}{r}11.21 \% \\
12\end{array}$ & $\begin{array}{r}13.08 \% \\
14\end{array}$ & $\begin{array}{r}6.54 \% \\
7\end{array}$ & $\begin{array}{r}3.74 \% \\
4\end{array}$ & $\begin{array}{r}2.80 \% \\
3\end{array}$ & $\begin{array}{r}5.61 \% \\
6\end{array}$ & 107 \\
\hline $\begin{array}{l}\text { Population identification and } \\
\text { physical/compositional } \\
\text { characterization }\end{array}$ & $\begin{array}{r}24.07 \% \\
26\end{array}$ & $\begin{array}{r}21.30 \% \\
23\end{array}$ & $\begin{array}{r}24.07 \% \\
26\end{array}$ & $\begin{array}{r}9.26 \% \\
10\end{array}$ & $\begin{array}{r}10.19 \% \\
11\end{array}$ & $\begin{array}{r}6.48 \% \\
7\end{array}$ & $\begin{array}{r}2.78 \% \\
3\end{array}$ & $\begin{array}{r}0.93 \% \\
1\end{array}$ & $\begin{array}{r}0.93 \% \\
1\end{array}$ & 108 \\
\hline $\begin{array}{l}\text { Population sources and sinks } \\
\text { (dynamical and collisional } \\
\text { evolution) }\end{array}$ & $\begin{array}{r}1.96 \% \\
2\end{array}$ & $\begin{array}{r}14.71 \% \\
15\end{array}$ & $\begin{array}{r}10.78 \% \\
11\end{array}$ & $\begin{array}{r}25.49 \% \\
26\end{array}$ & $\begin{array}{r}11.76 \% \\
12\end{array}$ & $\begin{array}{r}12.75 \% \\
13\end{array}$ & $\begin{array}{r}16.67 \% \\
17\end{array}$ & $\begin{array}{r}4.90 \% \\
5\end{array}$ & $\begin{array}{r}0.98 \% \\
1\end{array}$ & 102 \\
\hline $\begin{array}{l}\text { Comparing the history and } \\
\text { processes of our Solar } \\
\text { System with other solar } \\
\text { systems (e.g.,interstellar } \\
\text { objects, exoplanet systems) }\end{array}$ & $\begin{array}{r}1.90 \% \\
2\end{array}$ & $\begin{array}{r}9.52 \% \\
10\end{array}$ & $\begin{array}{r}11.43 \% \\
12\end{array}$ & $\begin{array}{r}13.33 \% \\
14\end{array}$ & $\begin{array}{r}19.05 \% \\
20\end{array}$ & $\begin{array}{r}19.05 \% \\
20\end{array}$ & $\begin{array}{r}11.43 \% \\
12\end{array}$ & $\begin{array}{r}10.48 \% \\
11\end{array}$ & $\begin{array}{r}3.81 \% \\
4\end{array}$ & 105 \\
\hline $\begin{array}{l}\text { Understanding how the } \\
\text { materials that initiate life } \\
\text { were delivered to the } \\
\text { habitable zone/Earth }\end{array}$ & $\begin{array}{r}9.26 \% \\
10\end{array}$ & $\begin{array}{r}6.48 \% \\
7\end{array}$ & $\begin{array}{r}9.26 \% \\
10\end{array}$ & $\begin{array}{r}12.96 \% \\
14\end{array}$ & $\begin{array}{r}15.74 \% \\
17\end{array}$ & $\begin{array}{r}20.37 \% \\
22\end{array}$ & $\begin{array}{r}12.04 \% \\
13\end{array}$ & $\begin{array}{r}9.26 \% \\
10\end{array}$ & $\begin{array}{r}4.63 \% \\
5\end{array}$ & 108 \\
\hline $\begin{array}{l}\text { Determining early conditions } \\
\text { in the Solar System (e.g., } \\
\text { compositional gradient, early } \\
\text { formationhistory) }\end{array}$ & $\begin{array}{r}18.35 \% \\
20\end{array}$ & $\begin{array}{r}19.27 \% \\
21\end{array}$ & $\begin{array}{r}9.17 \% \\
10\end{array}$ & $\begin{array}{r}10.09 \% \\
11\end{array}$ & $\begin{array}{r}15.60 \% \\
17\end{array}$ & $\begin{array}{r}9.17 \% \\
10\end{array}$ & $\begin{array}{r}9.17 \% \\
10\end{array}$ & $\begin{array}{r}8.26 \% \\
9\end{array}$ & $\begin{array}{r}0.92 \% \\
1\end{array}$ & 109 \\
\hline $\begin{array}{l}\text { Searching for extant } \\
\text { habitable zones }\end{array}$ & $\begin{array}{r}1.96 \% \\
2\end{array}$ & $\begin{array}{r}5.88 \% \\
6\end{array}$ & $\begin{array}{r}7.84 \% \\
8\end{array}$ & $\begin{array}{r}6.86 \% \\
7\end{array}$ & $\begin{array}{r}2.94 \% \\
3\end{array}$ & $\begin{array}{r}12.75 \% \\
13\end{array}$ & $\begin{array}{r}11.76 \% \\
12\end{array}$ & $\begin{array}{r}31.37 \% \\
32\end{array}$ & $\begin{array}{r}18.63 \% \\
19\end{array}$ & 102 \\
\hline $\begin{array}{l}\text { Completing the catalog of } \\
\text { PHAs and their } \\
\text { representative characteristics }\end{array}$ & $\begin{array}{r}24.27 \% \\
25\end{array}$ & $\begin{array}{r}10.68 \% \\
11\end{array}$ & $\begin{array}{r}7.77 \% \\
8\end{array}$ & $\begin{array}{r}11.65 \% \\
12\end{array}$ & $\begin{array}{r}4.85 \% \\
5\end{array}$ & $\begin{array}{r}5.83 \% \\
6\end{array}$ & $\begin{array}{r}13.59 \% \\
14\end{array}$ & $\begin{array}{r}14.56 \% \\
15\end{array}$ & $\begin{array}{r}6.80 \% \\
7\end{array}$ & 103 \\
\hline Other & $\begin{array}{r}21.05 \% \\
4\end{array}$ & $\begin{array}{r}0.00 \% \\
0\end{array}$ & $\begin{array}{r}5.26 \% \\
1\end{array}$ & $\begin{array}{r}0.00 \% \\
0\end{array}$ & $\begin{array}{r}10.53 \% \\
2\end{array}$ & $\begin{array}{r}0.00 \% \\
0\end{array}$ & $\begin{array}{r}5.26 \% \\
1\end{array}$ & $\begin{array}{r}10.53 \% \\
2\end{array}$ & $\begin{array}{r}47.37 \% \\
9\end{array}$ & 19 \\
\hline
\end{tabular}


QUESTION 8: HGHEST PRIORITY FLAGSHIP MISSION

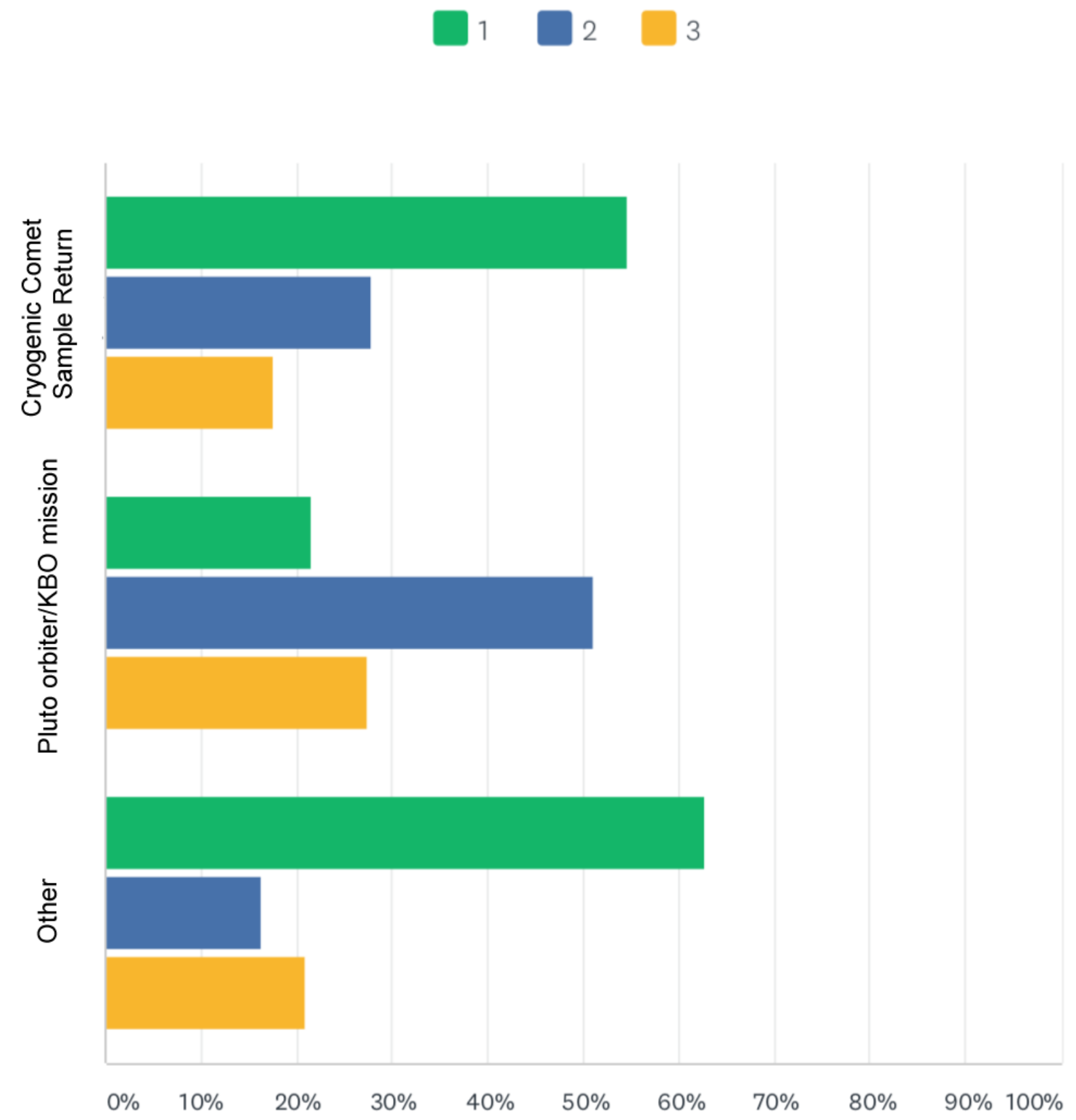

\section{QUESTION 10: HIGHEST PRIORITY NEW FRONTIERS MISSIONS}

Of the 121 respondents, the New Frontiers missions sorted on the basis of how many ranked then in the top three for priority (see table below) are:

57 - Comet surface sample return 
45 - Ceres lander

44 - Multiple main belt asteroid rendezvous

39 - Multiple target flyby of satellite (e.g., Triton) and small TNO

39 - Mega-multiple flybys of main belt asteroids

36 - Main-belt asteroid sample return

32 - Flyby of an explored ice dwarf (e.g., Haumea)

21 - Jupiter Trojan flyby

14 - Other (please specify)

\begin{tabular}{|c|c|c|c|c|c|c|c|c|c|c|}
\hline & 1 & 2 & 3 & 4 & 5 & 6 & 7 & 8 & 9 & TOTAL \\
\hline \multirow{2}{*}{$\begin{array}{l}\text { Main-belt asteroid } \\
\text { sample return }\end{array}$} & $8.65 \%$ & $19.23 \%$ & $6.73 \%$ & $8.65 \%$ & $9.62 \%$ & $12.50 \%$ & $10.58 \%$ & $17.31 \%$ & $6.73 \%$ & \\
\hline & 9 & 20 & 7 & 9 & 10 & 13 & 11 & 18 & 7 & 104 \\
\hline \multirow{2}{*}{$\begin{array}{l}\text { Comet surface sample } \\
\text { return }\end{array}$} & $23.15 \%$ & $12.96 \%$ & $16.67 \%$ & $11.11 \%$ & $7.41 \%$ & $3.70 \%$ & $12.96 \%$ & $8.33 \%$ & $3.70 \%$ & \\
\hline & 25 & 14 & 18 & 12 & 8 & 4 & 14 & 9 & 4 & 108 \\
\hline \multirow{2}{*}{$\begin{array}{l}\text { Multiple target flyby of } \\
\text { satellite (e.g., Triton) } \\
\text { and small TNO }\end{array}$} & $10.28 \%$ & $15.89 \%$ & $10.28 \%$ & $14.02 \%$ & $14.95 \%$ & $13.08 \%$ & $7.48 \%$ & $11.21 \%$ & $2.80 \%$ & \\
\hline & 11 & 17 & 11 & 15 & 16 & 14 & 8 & 12 & 3 & 107 \\
\hline \multirow{2}{*}{$\begin{array}{l}\text { Mega-multiple flybys of } \\
\text { main belt asteroids }\end{array}$} & $7.62 \%$ & $12.38 \%$ & $17.14 \%$ & $11.43 \%$ & $14.29 \%$ & $12.38 \%$ & $12.38 \%$ & $11.43 \%$ & $0.95 \%$ & \\
\hline & 8 & 13 & 18 & 12 & 15 & 13 & 13 & 12 & 1 & 105 \\
\hline \multirow{2}{*}{$\begin{array}{l}\text { Jupiter Trojan } \\
\text { rendezvous }\end{array}$} & $4.00 \%$ & $7.00 \%$ & $10.00 \%$ & $14.00 \%$ & $13.00 \%$ & $17.00 \%$ & $13.00 \%$ & $14.00 \%$ & $8.00 \%$ & \\
\hline & 4 & 7 & 10 & 14 & 13 & 17 & 13 & 14 & 8 & 100 \\
\hline \multirow{2}{*}{$\begin{array}{l}\text { Flyby of an unexplored } \\
\text { ice dwarf } \\
\text { (e.g.,Haumea) }\end{array}$} & $11.43 \%$ & $8.57 \%$ & $10.48 \%$ & $15.24 \%$ & $13.33 \%$ & $12.38 \%$ & $11.43 \%$ & $12.38 \%$ & $4.76 \%$ & \\
\hline & 12 & 9 & 11 & 16 & 14 & 13 & 12 & 13 & 5 & 105 \\
\hline \multirow{2}{*}{$\begin{array}{l}\text { Multiple main belt } \\
\text { asteroid rendezvous }\end{array}$} & $13.76 \%$ & $14.68 \%$ & $11.93 \%$ & $11.01 \%$ & $18.35 \%$ & $9.17 \%$ & $14.68 \%$ & $1.83 \%$ & $4.59 \%$ & \\
\hline & 15 & 16 & 13 & 12 & 20 & 10 & 16 & 2 & 5 & 109 \\
\hline \multirow[t]{2}{*}{ Ceres lander } & $13.89 \%$ & $12.04 \%$ & $15.74 \%$ & $11.11 \%$ & $6.48 \%$ & $12.96 \%$ & $12.96 \%$ & $12.04 \%$ & $2.78 \%$ & \\
\hline & 15 & 13 & 17 & 12 & 7 & 14 & 14 & 13 & 3 & 108 \\
\hline \multirow[t]{2}{*}{ Other } & $44.44 \%$ & $3.70 \%$ & $3.70 \%$ & $11.11 \%$ & $7.41 \%$ & $0.00 \%$ & $0.00 \%$ & $3.70 \%$ & $25.93 \%$ & \\
\hline & 12 & 1 & 1 & 3 & 2 & 0 & 0 & 1 & 7 & 27 \\
\hline
\end{tabular}

\section{Other:}

We need a wide survey of asteroids; A multiple JFC flyby mission; A comet observatory to get high resolution spectra of sun-grazing/disintegrating comets; Haumea; small bodies orbiting or active in the outer Solar System; Jupiter Trojan rendezvous listed below other options here under the impression that OKEANOS Trojan rendezvous may be further considered by JAXA; Long term rendezvous (full orbit) with a comet; multiple flybys of Halley-type/Oort cloud comets (multiple spacecraft "mission"); Rendezvous with one or more Centaurs

\section{QUESTION 12: WHAT ARE THE MOST IMPORTANT SCIENCE GOALS THAT CAN BE ADDRESSED BY DISCOVERY-CLASS MISSIONS?}

Four pages of answers were generated by this question. The full list is on the SBAG website.

Here is a summary, including only small bodies and not in any particular order:

Characterize a wide variety of objects

What are the characteristics of the Solar System that led to the origin of life? 
How did life begin and evolve on Earth and has it evolved elsewhere in the Solar System? Exploration of water worlds in small bodies, such as Ceres

In-situ mass spectrometry of Main belt comets

Determine how water and organics are distributed throughout the solar system and how they have been processed over time

Detection, cataloguing of NEOs and MBAs alike along with determining their size / albedo (e.g. NEOCAM) and basic characterization of NEOs (extending to multiple-body ones) and their geophysics

Determining the interior structure of small bodies, and how that structure has evolved over time

Determine how and where comets formed. Measure the compositions of a statistically-

representative sample of comets on scales down to the individual grains from which we can infer

the conditions of formation

Learn which comets are least-altered since the Solar System's birth

What is the nature of activity on Main Belt Comets?

Multi-comet flyby

Multi-Centaur flyby

What is the nature of organic chemistry on Ceres?

What endogenic geologic processes shaped Ceres surface/structure and how long did they operate/are they still operating?

Understanding the early evolution of the Solar System

Small body / rubble pile mechanics

Discovery-class missions should investigate knowledge gaps such that they enable better

formulated NF and Flagship missions, and they should also set out scientific objectives that will provide context to tie together ground-based observations and interpretations and spacecraft observations and interpretations

Image an Oort Cloud object

Fast response to an exciting object such as an interstellar comet

Survey of the Jovian irregular moons

\section{QUESTION 13: WHAT ARE THE HIGHEST PRIORITY RESEARCH FACILITIES THAT NEED TO BE DEVELOPED AND/OR SUPPORTED?}

\begin{tabular}{|c|c|c|c|c|c|c|c|}
\hline & 1 & 2 & 3 & 4 & 5 & 6 & TOTAL \\
\hline \multirow[t]{2}{*}{ Access to large aperture ground-based telescope facilities } & $26.47 \%$ & $19.61 \%$ & $24.51 \%$ & $18.63 \%$ & $8.82 \%$ & $1.96 \%$ & \\
\hline & 27 & 20 & 25 & 19 & 9 & 2 & 102 \\
\hline \multirow[t]{2}{*}{ Radar facilities } & $18.69 \%$ & $18.69 \%$ & $29.91 \%$ & $20.56 \%$ & $8.41 \%$ & $3.74 \%$ & \\
\hline & 20 & 20 & 32 & 22 & 9 & 4 & 107 \\
\hline \multirow{2}{*}{$\begin{array}{l}\text { Modest aperture ground-based telescope facilities } \\
\text { dedicated to primitive bodies search andcharacterization }\end{array}$} & $20.75 \%$ & $33.02 \%$ & $20.75 \%$ & $16.98 \%$ & $7.55 \%$ & $0.94 \%$ & \\
\hline & 22 & 35 & 22 & 18 & 8 & 1 & 106 \\
\hline \multirow{2}{*}{$\begin{array}{l}\text { Laboratory support for meteorite studies, and returned } \\
\text { sample/analog characterization, includingadvanced } \\
\text { curation facilities such as cold curation of volatiles, long- } \\
\text { term containment, andanalysis of organic materials }\end{array}$} & $30.63 \%$ & $18.02 \%$ & $13.51 \%$ & $23.42 \%$ & $8.11 \%$ & $6.31 \%$ & \\
\hline & 34 & 20 & 15 & 26 & 9 & 7 & 111 \\
\hline \multirow[t]{2}{*}{ Computational } & $7.77 \%$ & $10.68 \%$ & $9.71 \%$ & $13.59 \%$ & $53.40 \%$ & $4.85 \%$ & \\
\hline & 8 & 11 & 10 & 14 & 55 & 5 & 103 \\
\hline \multirow[t]{2}{*}{ Other } & $15.00 \%$ & $10.00 \%$ & $0.00 \%$ & $10.00 \%$ & $10.00 \%$ & $55.00 \%$ & \\
\hline & 3 & 2 & 0 & 2 & 2 & 11 & 20 \\
\hline
\end{tabular}




\section{QUESTION 15: BALANCING PRIORITIES - IN THE EVENT OF NEGATIVE BUDGET PRESSURE ON THE PLANETARY BUDGET, WHAT IS THE PRIORITY FOR PRESERVING PROGRAM FUNDING?}

\begin{tabular}{|c|c|c|c|c|c|c|c|}
\hline & 1 & 2 & 3 & 4 & 5 & 6 & TOTAL \\
\hline New Frontiers-class missions & $\begin{array}{r}12.28 \% \\
14\end{array}$ & $\begin{array}{r}14.04 \% \\
16\end{array}$ & $\begin{array}{r}32.46 \% \\
37\end{array}$ & $\begin{array}{r}29.82 \% \\
34\end{array}$ & $\begin{array}{r}11.40 \% \\
13\end{array}$ & $\begin{array}{r}0.00 \% \\
0\end{array}$ & 114 \\
\hline Discovery-class missions & $\begin{array}{r}15.79 \% \\
18\end{array}$ & $\begin{array}{r}43.86 \% \\
50\end{array}$ & $\begin{array}{r}18.42 \% \\
21\end{array}$ & $\begin{array}{r}16.67 \% \\
19\end{array}$ & $\begin{array}{r}4.39 \% \\
5\end{array}$ & $\begin{array}{r}0.88 \% \\
1\end{array}$ & 114 \\
\hline Technology development programs & $\begin{array}{r}6.25 \% \\
7\end{array}$ & $\begin{array}{r}12.50 \% \\
14\end{array}$ & $\begin{array}{r}27.68 \% \\
31\end{array}$ & $\begin{array}{r}29.46 \% \\
33\end{array}$ & $\begin{array}{r}22.32 \% \\
25\end{array}$ & $\begin{array}{r}1.79 \% \\
2\end{array}$ & 112 \\
\hline Flagship-class missions & $\begin{array}{r}5.36 \% \\
6\end{array}$ & $\begin{array}{r}9.82 \% \\
11\end{array}$ & $\begin{array}{r}8.93 \% \\
10\end{array}$ & $\begin{array}{r}16.96 \% \\
19\end{array}$ & $\begin{array}{r}49.11 \% \\
55\end{array}$ & $\begin{array}{r}9.82 \% \\
11\end{array}$ & 112 \\
\hline Research and Data Analysis programs & $\begin{array}{r}57.39 \% \\
66\end{array}$ & $\begin{array}{r}17.39 \% \\
20\end{array}$ & $\begin{array}{r}7.83 \% \\
9\end{array}$ & $\begin{array}{r}5.22 \% \\
6\end{array}$ & $\begin{array}{r}7.83 \% \\
9\end{array}$ & $\begin{array}{r}4.35 \% \\
5\end{array}$ & 115 \\
\hline Other & $\begin{array}{r}22.22 \% \\
4\end{array}$ & $\begin{array}{r}11.11 \% \\
2\end{array}$ & $\begin{array}{r}22.22 \% \\
4\end{array}$ & $\begin{array}{r}0.00 \% \\
0\end{array}$ & $\begin{array}{r}0.00 \% \\
0\end{array}$ & $\begin{array}{r}44.44 \% \\
8\end{array}$ & 18 \\
\hline
\end{tabular}

Research and Data Analysis programs are the clear highest priority for preservation in the event of insufficient funding for the planetary budget overall. This makes sense as they are the integrative effort for putting together knowledge from diverse missions and basic research, they provide the basis and justification for future missions and they provide continuing return on investment from past missions. These programs are also a primary source of funding for training the next generation of planetary scientists. They also provide core support for the American planetary community as a whole, ensuring we maintain a diversely capable community for the wide breadth of exploration of the Solar System and solar systems around other stars that is undertaken by the US government on behalf of the people.

The Discovery program is the clear second choice, particularly when considering both $1^{\text {st }}$ and $2^{\text {nd }}$ priority voting. This offers the most frequent class of mission (nominally one every two years, with New Frontiers being once every five years and flagships once a decade). It allows for a greater diversity of targets to be visited over a decade, even extending into the outer solar system as technologies improve.

\section{QUESTION 17: WHAT TECHNOLOGY INVESTMENTS DO YOU RECOMMEND?}

There are four pages on the website: https://www.lpi.usra.edu/decadal/sbag/ 